\title{
CAPA, ORELHAS E QUARTA CAPA COMO ESPACCOS ENUNCIATIVOS DE PROMOÇÃO DE OBRAS LITERÁRIAS
}

\author{
Front Cover, Flaps, and Back Cover Portada, solapas y página de créditos \\ as Enunciative Spaces como espacios enunciativos \\ to Promote Literary Works de la promoción de obras literarias
}

\author{
Vinícius Lourenço Linhares* \\ Instituto Federal de Minas Gerais, Departamento de Linguagens, Congonhas, MG, Brasil
}

\begin{abstract}
Resumo: A partir da aproximação entre teoria da enunciação e o processo de produção e editoração do livro, este artigo analisa a encenação de alguns agentes envolvidos na cadeia editorial do livro $O$ sol na cabeça, do escritor brasileiro Geovani Martins, relativamente à promoção/divulgação e difusão do referido livro. Embasam este trabalho as discussões de Araújo (2012), Cavallo e Chartier (2001), Chartier (1998) e Thompson (2012) sobre processos de edição. As discussões envolvendo a enunciação estão calcadas nos estudos de Benveniste (1989; 1995), Bakhtin/Volochínov (2009) e Bakhtin (2010), além de se valer da visão de Marx (1996) sobre a mercadoria no contexto da economia capitalista.
\end{abstract}

Palavras-chave: Cadeia editorial. Divulgação. Enunciação. Literatura. Livro.

\begin{abstract}
Based on the approximation between the Theory of Enunciation and the process of book production and publishing, this paper analyzes the participation of some agents that have been involved in the publishing supply chain of the book $O$ sol na Cabeça, by the Brazilian writer Geovani Martins, concerning the promotion/publicizing of his book. In order to discussing the editing processes, this paper uses the discussions of Araújo (2012), Cavallo and Chartier (2001), Chartier (1998), and Thompson (2012). About the discussions involving the enunciation, the theoretical bases are the studies of Benveniste (1989, 1995), Bakhtin/Volóchinov (2009) and Bakhtin (2010). Furthermore, the Marx's (1996) view regarding the merchandise in the context of the capitalist economy.
\end{abstract}

Keywords: Publishing supply chain. Promotion. Enunciation. Literature. Book.

Resumen: A partir de la aproximación entre teoría de la enunciación y el proceso de producción y edición del libro, este artículo investiga la escenificación de algunos agentes involucrados en la cadena editorial del libro $O$ sol na cabeça, del escritor brasileño Geovani Martins, respecto a la promoción/divulgación del referido libro. Este trabajo se basa en las discusiones de Araújo (2012), Cavallo y Chartier (2001), Chartier (1998) y Thompson (2012) sobre procesos de edición. Las discusiones que involucran la enunciación están basadas en los estudios de Benveniste (1989; 1995), Bajtín/Volóshinov (2009) y Bajtín (2010), además de valerse de la visión de Marx (1996) respecto a la mercancía en el contexto de la economía capitalista.

Palabras clave: Cadena editorial. Divulgación. Enunciación. Literatura. Libro.

* Docente no Instituto Federal de Minas Gerais (IFMG), Campus Congonhas, atuando nos cursos técnicos, na Licenciatura em Letras e demais cursos superiores - Departamento de Linguagens. Doutorando em Literaturas de Língua Portuguesa, na PUC Minas, com bolsa de pesquisa da Capes II. ORCID: https://orcid.org/0000-0002-3849-8217. E-mail: vini1460@yahoo.com.br. 


\title{
10 LIVRO COMO PRODUTO FORJADO NA/PELA CADEIA EDITORIAL
}

Em seu conhecido texto $O$ caráter fetichista da mercadoria e seu segredo, Marx (1996) argumenta que tal característica, inerente à mercadoria, decorre do apagamento do trabalho humano empregado na confecção de um produto. Tão logo esse produto assume a forma de mercadoria, todo o trabalho humano aí envolvido é apagado, sumido "magicamente". Por isso, Marx (1996) afirma que "os produtos do cérebro humano parecem dotados de vida própria, figuras autônomas, que mantêm relações entre si e com os homens." (MARX, 1996, p. 198). No caso de uma cadeia editorial, sobretudo das grandes companhias editoriais, esse caráter fetichista da mercadoria mostra-se de modo mais acentuado porque o produto final dessa cadeia - o livro - vem envolvido numa aura de erudição e distinção social que acaba por separar (ou segregar?) aqueles que leem muitos livros, devorando-os, como muito se ouve, daqueles que não leem ou leem poucos livros.

Destitui-se, dessa forma, entre outras, o livro de seu aspecto de mercadoria, fazendo com que se esqueça que até chegar às mãos do leitor, o livro passa por um amplo processo de editoração que vai desde a escrita do texto pelos autores até a impressão de sua versão final, que será comercializada. Entre a escrita do texto e sua versão final, transformada em livro e comercializada, outros processos e profissionais da área editorial são interrelacionados e coordenados numa ampla cadeia editorial. No âmbito dessa cadeia, o livro, que para cada leitor pode evocar distintas representações e sentimentos - prazer, sofrimento, conhecimento, partilha, etc. - é um produto. Circulando numa economia capitalista, como é o caso da nossa, esse produto está submetido a regras de funcionamento que obedecem às máximas de custo, benefício e lucratividade. Roger Chartier e Guglielmo Cavallo (2001), importantes pesquisadores dedicados à história do livro e da leitura no Ocidente, afirmam que

\begin{abstract}
Os autores não escrevem livros: não, escrevem textos que se tornam objetos escritos manuscritos, gravados, impressos e, hoje, informatizados - manejados de diferentes formas por leitores de carne e osso cujas maneiras de ler variam de acordo com as épocas, os lugares e os ambientes. (CAVALLO; CHARTIER, 2001, p. 20, tradução minha) ${ }^{1}$
\end{abstract}

Essa complexa cadeia editorial na qual se forja o livro, por sua vez, é movimentada por distintos saberes e técnicas de criação. Emanuel Araújo (2012), autor cuja obra é considerada fundamental para a área de processos editoriais, caracteriza a editoração como

[...] o conjunto de teorias, técnicas e aptidões artísticas e industriais destinadas ao planejamento, feitura e distribuição de um produto editorial. Em outras palavras, editoração é o gerenciamento da produção de uma publicação - livros, revistas, jornais, boletins, álbuns, cadernos, almanaques, etc. (ARAÚJO, 2012, p. 38)

\footnotetext{
${ }^{1} \mathrm{Na}$ edição consultada: "Los autores no escriben libros: no, escriben textos que se transforman en objetos escritos - manuscritos, grabados, impresos y, hoy, informatizados - manejados de diversa manera por unos lectores de carne y hueso cuyas maneras de leer varian con arreglo a los tiempos, los lugares y los ámbitos.”.
} 
Nesse processo, constam etapas de seleção do conteúdo, revisão, planejamento do projeto editorial, planejamento do projeto gráfico, execução (diagramação), revisão da diagramação, finalização e impressão (ou programação digital, se for o caso). Tais etapas, por sua vez, vão sendo movimentadas a partir de engrenagens que sustentam e fomentam o mercado editorial.

Sobre essa questão mercadológica, o sociólogo britânico John B. Thompson, importante pesquisador sobre os mecanismos e agentes envolvidos no funcionamento do mercado editorial em língua inglesa, propõe uma abordagem da cadeia editorial recorrendo às categorias de campo e capital, retomadas do também sociólogo, o francês Pierre Bourdieu ${ }^{2}$. A partir dessa retomada, Thompson (2013, p. 13-14) elenca cinco importantes tipos de capital que, na sua visão, são imprescindíveis à constituição e movimentação da cadeia editorial: o capital econômico, o capital humano, o capital social, o capital intelectual e o capital simbólico.

Segundo Thompson (2013, p. 15), o capital econômico diz respeito aos recursos financeiros acumulados. O capital humano está ligado aos profissionais empregados na empresa com distintos conhecimentos e habilidades. $\mathrm{O}$ capital social diz respeito à rede de contatos e relações construídas ao longo do tempo por um indivíduo ou pela organização empresarial. O capital intelectual diz respeito aos direitos que um editor possui ou controla em conteúdo intelectual. Tais direitos são lastreados nos contratos com autores e outros órgãos que podem ser explorados através de vendas e publicações. E, por fim, o capital simbólico é o prestígio acumulado e o status associado à editora. Tudo isso, por sua vez, não se constitui de modo isolado. Ao contrário, é constantemente interrelacionado na constituição e geração de valor na/para a cadeia editorial, tratada por Thompson (2012) como um campo de disputas, justamente por envolver capital e poder:

Um campo é um espaço estruturado de posições sociais que podem ser ocupadas por agentes e organizações, e no qual a posição de qualquer agente ou organização depende do tipo e quantidade de recursos ou "capital" que eles têm à sua disposição. Qualquer arena social um setor empresarial, uma esfera da educação, um domínio do esporte - pode ser tratada como um campo no qual agentes e organizações estão ligados em relações de cooperação, competição e interdependência. Os mercados são uma parte importante de alguns campos, mas os campos são sempre mais que os mercados. Eles são compostos de agentes e organizações, de diferentes tipos e quantidades de poder e recursos, de uma variedade de práticas e de formas específicas de competição, colaboração e recompensa. (THOMPSON, 2012, p. 14, tradução minha) $)^{3}$.

${ }^{2}$ Bourdieu afirma que não é possível explicar o mundo social sem retomar o capital em todas as suas formas de manifestação, e não apenas econômica. Para o sociólogo, as formas de troca na sociedade capitalista, cujo capital econômico é a forma mais aparente e material, "podem se apresentar na forma imaterial do capital cultural, ou do capital social, e vice-versa." (BOURDIEU, 1986, p.242, tradução minha). Quanto ao conceito de campo, Bourdieu afirma que se "trata de um espaço social estruturado, um campo de forças - há dominantes e dominados, há relações constantes, permanentes, de desigualdade, que se exercem no interior desse espaço - que é também um campo de lutas para transformar ou conservar esse campo de forças.” (BOURDIEU, 1997, p. 57).

${ }^{3}$ No original: "A field is a structured space of social positions which can be occupied by agents and organizations, and in which the position of any agent or organization depends on the type and quantity of resources or 'capital' they have at their disposal. Any social arena - a business sector, a sphere of education, a domain of sport - can be treated as a field in which agents and organizations are linked together in relations of cooperation, competition and interdependency. Markets are an important part of some fields, but fields are always more than markets. They are made up of agents and organizations, of different kinds and quantities of power and resources, of a variety of practices and of specific forms of competition, collaboration and reward." (THOMPSON, 2012, p. 14). 
No esquema formulado por Thompson (2012), retomado do autor na figura 1, para representar a cadeia editorial, estão explicitados os agentes nela envolvidos e sobre a qual o autor argumenta ser ela também "uma cadeia de valor, no sentido de que cada um dos links supostamente acrescenta algum 'valor' no processo." (THOMPSON, 2012, p. 19, tradução minha) $)^{4}$.

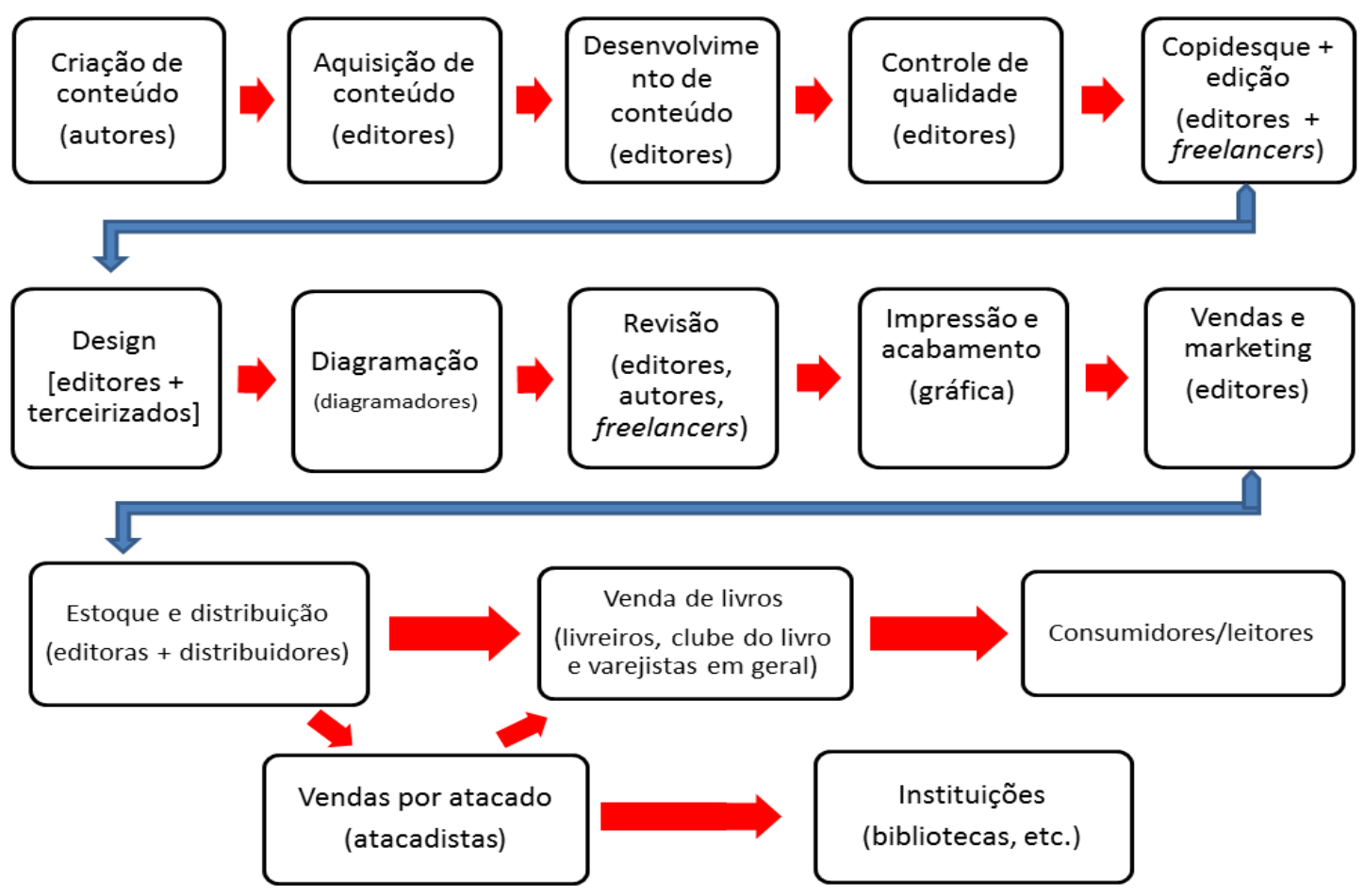

Figura 1 - Esquema da Cadeia editorial

Fonte: Thompson (2012, p.19). Tradução e reelaboração do esquema feitas pelo autor.

Sem esgotar todos os aspectos que envolvem a cadeia editorial, essa breve exposição é suficiente para se ter em mente que: 1) autores não escrevem livros, escrevem textos que serão transformados em livros; 2) livros são produtos que, produzidos numa economia capitalista, assumem a forma mercadoria; 3 ) do estágio inicial ao estágio final, o livro, como produto, é forjado numa cadeia composta por diversos agentes cujas ações estão sempre voltadas para a atribuição de distintos valores a esse mesmo produto. Interessa a este artigo, pois, discutir a interação, do ponto de vista enunciativo, de alguns desses agentes que movimentam a cadeia editorial, especificamente na promoção e difusão do livro $O$ sol na cabeça, de Geovani Martins. Tal interação, conforme será demonstrado, evidencia um jogo de cena marcado por, pelo menos, dois movimentos: por um lado, o esforço editorial em construir a imagem de credibilidade para o jovem e debutante autor do livro diante de público potencial; por outro lado, a escamoteação de algumas relações de poder que movimentam essa mesma cadeia.

\footnotetext{
${ }^{4}$ No original: "The publishing chain is also a value chain in the sense that each of the links purportedly adds some "value' in the process." (THOMPSON, 2012, p. 19).
} 
As considerações tecidas na seção anterior sobre a criação do produto livro na/pela cadeia editorial nos permite avançar para um outro desdobramento desse produto: sua encenação numa cadeia enunciativa. Comecemos pensando numa cadeia produtiva. Seja ela qual for, é sempre formada por homens e mulheres concretamente situados em um tempo e espaço. Mais que isso, é a ação entre esses agentes - a inter(ação) - que gera essa cadeia. Do ponto de vista da linguagem, uma lógica de realização semelhante acontece. São homens e mulheres falando com outros homens e mulheres que existem no mundo, numa ampla e complexa cadeia enunciativa. A esse respeito, Émile Benveniste (1995), em seus seminais textos sobre linguagem, enunciação e subjetividade, afirma que:

\begin{abstract}
A linguagem está na natureza do homem que não a fabricou. Inclinamo-nos sempre para a imaginação ingênua de um período original, em que um homem completo descobriria um semelhante igualmente completo e, entre eles, pouco a pouco, se elaboraria a linguagem. Isso é pura ficção. Não atingimos nunca o homem separado da linguagem e não o vemos nunca inventado-a. Não atingimos jamais o homem reduzido a si mesmo e procurando conceber a existência do outro. É um homem falando que encontramos no mundo, um homem falando com outro homem, e a linguagem ensina a própria definição do homem. (BENVENISTE, 1995, p. 285, grifos meus).
\end{abstract}

O pressuposto de que não existe nenhum ser humano reduzido a si mesmo e que é um homem falando que encontramos no mundo permite a Benveniste (1995) postular que "todo homem se coloca em sua individualidade enquanto eu por oposição a tu e ele. Este comportamento será julgado “instintivo"”. (BENVENISTE, 1995, p. 68, grifos do autor). O mesmo pressuposto de que só existe um homem diante do outro também é a defesa feita por Bakhtin e Volochínov (2009) e Bakhtin (2010) em seus estudos sobre a linguagem. A palavra é sempre socialmente orientada e habitada, simultaneamente, pela valoração de quem a enuncia em conflito com a valoração do outro a quem ela é dirigida, de modo que as situações de interação se constituem por conflitos e tensionamentos da palavra posta em disputa em distintas esferas da atividade humana em um processo marcadamente dialógico (BAKHTIN, 2010).

Também negando o aspecto instrumental da linguagem, Bakhtin e Volochínov (2009) dizem que "[...] não se trata de um meio ou de um instrumento que serve para atingir fins exteriores a ela, mas de um organismo vivo, funcionando em si e para si. Essa autossuficiência criadora da linguagem manifesta-se na imaginação linguística." (BAKHTIN; VOLOCHÍNOV, 2009, p.190). É a partir desse paradigma, portanto, por meio do qual se pensa a linguagem em termos de elaboração e criatividade, sendo uma atividade constitutiva do homem, que se insere o conceito de enunciação, tomado aqui como operador de análise deste trabalho.

Afirma Benveniste (1989) que "[...] o ato individual de apropriação da língua introduz aquele que fala em sua fala. Este é um dado constitutivo da enunciação. A presença do locutor em sua enunciação faz com que cada instância de discurso constitua um centro de referência interno." (BENVENISTE, 1989, p. 84). Esse ato de apropriação individual, por sua vez, só pode acontecer diante do outro, expresso pelo pronome de 
segunda pessoa TU, o que implica um direcionamento mútuo e reversível das posições enunciativas. E, uma vez que o par EU e TU, interativamente, criam a correferenciação no aqui/agora da enunciação, argumenta Benveniste (1989), o processo de referenciação igualmente compõe a enunciação.

Bakhtin e Volochínov (2009), por sua vez, colocam em evidência o intrínseco traço social que marca a enunciação, a qual se caracteriza por ser

[...] o produto da interação de dois indivíduos socialmente organizados e, mesmo que não haja um interlocutor real, este pode ser substituído pelo representante médio do grupo social ao qual pertence o locutor. A palavra dirige-se a um interlocutor: ela é função da pessoa desse interlocutor: variará se se tratar de uma pessoa do mesmo grupo social ou não, se esta for inferior ou superior na hierarquia social, se estiver ligada ao locutor por laços sociais mais ou menos estreitos (pai, mãe, marido, etc.). (BAKHTIN; VOLOCHÍNOV, 2009, p.116, grifos meus).

Como se pode observar, a enunciação é um processo que prevê sempre a interação de indivíduos social e concretamente situados num determinado tempo e espaço que correferenciam um determinado objeto do discurso. Esse processo, por sua vez, nunca é estático e sempre se desdobra em uma cadeia enunciativa ampla que está sempre em contato com outras enunciações. Tomando, portanto, a realização linguística das categorias que compõem a enunciação - o EU diante do TU, coconstruindo uma referenciação, representada pelo pronome ELE, no AQUI-AGORA enunciativo - o intuito é aproximar alguns agentes envolvidos na cadeia editorial de produção do livro à sua encenação na cadeia enunciativa.

Dito de outro modo: o livro como um objeto, um produto a ser forjado e, finalmente vendido, passa por várias etapas, entre as quais a etapa de divulgação e promoção. Essas duas etapas, compreendidas na fase do marketing, envolvem, entre outros agentes, editores, resenhistas, booktubers ${ }^{5}$, prefaciadores, leitores de clubes de livros, bibliotecários, colunistas, críticos literários e demais comentaristas, de modo amplo, que podem ser outros autores que se tornam leitores do livro em divulgação, por exemplo.

Ocupando distintas posições na cadeia editorial, os referidos agentes, antes de ocuparem uma posição específica e especializada na divulgação do livro, são, primeiramente, leitores do livro. E observar a enunciação desses distintos agentes sobre o livro em divulgação se mostra um excelente exercício no sentido de se perceber como o livro em questão está sendo referenciado. Com que predicações esse livro, que é, além de um produto, uma mercadoria, é difundido, divulgado e promovido a fim de ser vendido.

Para analisar como se dá a inter-relação de alguns agentes envolvidos na cadeia editorial do livro aqui analisado, serão considerados: 1) o comentário adesivado na capa do livro; 2) o texto de apresentação presente nas orelhas do livro, assinado pelo também escritor Antonio Prata e, 3); comentários feitos por João Moreira Salles e Chico Buarque e apresentados na quarta capa do livro $O$ sol na cabeça. Frise-se, portanto, que o elo da

\footnotetext{
${ }^{5}$ Booktuber é uma expressão para a definição de quem produz algum canal no YouTube focado em livros e literatura. É a junção de 'book' (livro) e 'tuber', sufixo do termo youtuber (aquele que produz conteúdo na internet). Os booktubers comentam e divulgam livros das mais diversas temáticas.
} 
cadeia editorial focalizado é o de marketing, responsável, no caso, pela promoção da obra. Essa promoção será considerada a partir do processamento enunciativo nos supracitados paratextos, que compõem a materialidade do próprio livro, constituindo-se, esses paratextos, como uma força divulgadora, dentre outras, tanto da obra quanto do autor.

\section{O SOL NA CABEÇA: A CADEIA EDITORIAL AUTORIZADA A ENUNCIAR}

O sol na cabeça reúne treze contos do escritor carioca Geovani Martins e foi publicado em 2018, pela Companhia das letras. O autor, nascido em 1991, em Bangu/RJ, trabalhou como "homem-placa" e atendente de lanchonete, publicou alguns de seus contos na revista Setor $X$ e, em 2013 e 2015, participou das oficinas da Festa Literária das Periferias - FLUP - além de ter tido duas participações, como convidado, na Festa Literária Internacional de Paraty, a FLIP.

É interessante ressaltar que Geovani Martins, apesar de não ser tão conhecido pelo grande público leitor, é publicado na/pela Companhia das Letras, a maior editora brasileira, tradicionalmente especializada em publicações nas áreas de Literatura e Ciências Humanas com diversos títulos agraciados com importantes prêmios nacionais e internacionais. Assim, ao apostar em Geovani Martins, a editora mobiliza seu amplo capital simbólico, seu prestígio editorial para lançar, como anunciado em caixa alta na capa do livro, "o novo fenômeno literário brasileiro vendido para 9 países”. Esse anúncio, colado à capa à semelhança de um selo de qualidade, visa exatamente atestar a garantia e procedência do livro a ser comprado. A própria seleção vocabular para predicar Geovani Martins - "o novo fenômeno" - constrói Geovani Martins como um autor extraordinário que, além de ser publicado no Brasil, também conquistou o mercado internacional, haja vista seu livro já ter sido disseminado em outros nove países. Esse "selo", assinado pela Companhia das Letras e afixado na capa do livro, vem imprimir valor simbólico à obra, destacando-a em relação a outras, além de construir Geovani Martins como um autor prodígio com potencial para surpreender seus leitores possíveis.

Esse primeiro comentário, portanto, funciona como uma das estratégias de promoção do livro e, possivelmente ${ }^{6}$, será o primeiro texto apreciativo sobre o livro com o qual o possível leitor/consumidor vai se deparar, em função de tal comentário estar localizado na capa do livro. Logo em seguida, nas duas orelhas do livro, lê-se o comentário feito por outro autor, Antonio Prata, também publicado na/pela Companhia das Letras. Prata é colunista da Folha de S. Paulo, roteirista e autor de literatura, contando com dez livros publicados, além de sempre transitar por diversos programas televisivos e outras mídias. Somado a todo esse capital simbólico e social, Antonio Prata é fillho de dois outros escritores, Mário Prata e Marta Goés, o que, certamente, conferiu-lhe distintos e suficientes capitais para ganhar visibilidade destacada, tanto no mercado editorial brasileiro, quanto na cena literária brasileira. Assim, podemos considerar Antonio Prata como um dos agentes de valor na cadeia de divulgação do livro de Geovani Martins, o que se atesta pelo comentário do autor sobre Martins e, por extensão, sobre o livro deste:

\footnotetext{
${ }^{6}$ Vale matizar ainda mais essa possibilidade, haja vista que outras formas de divulgação, que também participam da cadeia editorial, podem facilmente chegar ao leitor. É o caso de resenhas, divulgações em plataformas digitais diversas e, até mesmo, a propaganda de boca a boca.
} 
Vai chegar o dia em que a orelha de um livro do Geovani Martins poderá ignorar o fato de que ele é um escritor nascido em Bangu e morador da Rocinha ou do Vidigal, porque Geovani Martins é um escritor, ponto: quando fala de uma relação amorosa, em "A viagem"; sobre a infância, em "O caso da borboleta", ou sobre qualquer outro assunto, o faz com o talento e a sensibilidade de um narrador habilidoso, pouco importando a sua origem.

Neste primeiro livro, porém, a inspiração autobiográfica é clara, e a força dos contos é inseparável do lugar de onde o autor vê o mundo. Nos treze contos de $O$ sol na cabeça, acompanhamos a infância e a adolescência de garotos para quem às angústias e dificuldades próprias da idade soma-se a violência de crescer no lado menos favorecido da "Cidade partida", o Rio de Janeiro das primeiras décadas do século XXI.

Em "Rolézim", uma turma de adolescentes vai à praia no verão de 2015 , quando a PM fluminense, em nome do combate aos arrastões, fazia marcação cerrada aos meninos de favela que pretendessem chegar às areias da Zona Sul. Em "A história do Periquito e do Macaco", assistimos às mudanças ocorridas na Rocinha após a instalação da Unidade de Polícia Pacificadora, a UPP. Situado em 2013, quando a maioria da classe média carioca ainda via a iniciativa do secretário de Segurança José Beltrame como a panaceia contra todos os males, o conto mostra que, para a população sob o controle da polícia, o segundo $\mathrm{P}$ da sigla não era exatamente uma realidade. Em "Estação Padre Miguel", cinco amigos se veem sob a mira dos fuzis dos traficantes locais.

Nesses e nos outros contos, chama atenção a capacidade narrativa do escritor, pintando com cores vivas personagens e ambientes sem nunca perder o suspense e o foco na ação. $\mathrm{Na}$ literatura brasileira contemporânea, que tantas vezes negligencia a trama em favor de supostas experimentações formais, $O$ sol na cabeça surge como uma mais que bem-vinda novidade. (PRATA, Antonio [Orelha do livro])

Como de costume, a orelha de um livro abriga um gênero, cuja finalidade é apresentar, de maneira apreciativa, a obra em questão. Do mesmo modo, quem assina a orelha é normalmente conhecido e reconhecido na esfera discursiva à qual pertence o livro sobre o qual se fala. Lançando foco no conteúdo daquilo que Prata escreve na orelha de $O$ sol na cabeça, observa-se a construção de um enunciador que parece fazer "debutar" um novo autor para a comunidade leitora. Pelo menos para aqueles que podem e sabem ler. No primeiro parágrafo, Prata busca contemporizar a origem humilde e pobre de Geovani Martins, nascido em uma região de favelas na cidade do Rio de Janeiro, com uma qualificação que ganha valor em si mesma. É o que se pode comprovar em “... porque Geovani Martins é um escritor, ponto...”. A partir daí é possível ler dois efeitos: o primeiro, positivo, de que Geovani Martins é um escritor de fato talentoso e, por isso, a construção é incisiva, marcada com uma qualificação predicativa de cunho autocentrada: “... é um escritor, ponto...”. Por outro lado, o efeito laudatório pretendido pelo enunciador construído por Prata parece se chocar com as contradições próprias de nossa sociedade: nossa filogênese racista e classista, para se dizer o mínimo.

Veja-se aí insinuado que a origem periférica de Geovani Martins, de modo talvez determinista, inviabilizá-lo-ia de se tornar um escritor. Um ofício, tradicionalmente no caso do Brasil, exercido pelas camadas mais abastadas e, frequentemente, "herdado"

\footnotetext{
${ }^{7}$ Vale a pena frisar que Antonio Prata tem pais escritores. Principalmente seu pai, Mário Prata, goza de amplo prestígio na cena literária brasileira. Não quero discutir o talento ou não de Antonio Prata. Interessa-me frisar que, sob o rótulo de "talento" e demais louvações, pode estar escamoteada uma ampla rede de capitais - simbólicos, sociais, culturais e econômicos - tomados como naturais. Não se atentar para essa intrincada rede de capitais, criados, mantidos e herdados a partir de distintas relações de poder, é reforçar entre nós, ainda que de modo inconsciente, o preconceito nosso de cada dia, além do cínico discurso da meritocracia.
} 
Afinal, Bangu, Rocinha e Vidigal são complexos de favelas cariocas marcados pelo tráfico e pela ampla violência contra seus moradores, incluindo-se aí a violência do próprio Estado com o argumento de proteção e combate ao crime. Essa leitura ganha reforço ao final do referido parágrafo, quando o enunciador construído por Prata afirma que, na construção de seus contos, Geovani Martins os faz com "talento e a sensibilidade de um narrador habilidoso, pouco importando sua origem." (grifos meus). Novamente há uma contemporização entre a origem e o talento e a sensibilidade que, mais do que de um narrador, são atributos de Geovani Martins, na criação de seus narradores. Salientese que na referida contemporização, o segundo termo - a origem de Martins - como sugere o enunciador, não é relevante como atributo para um escritor que está "sendo debutado".

Avançando ainda mais, seria o caso de se perguntar: é pouco importante a origem de Geovani Martins ou essa origem "mancha" o produto anunciado? E, por isso, embora visível demais para simplesmente ser ignorada, essa origem precisa ser abrandada/retocada, - "pouco importando sua origem", diz Prata - para que os leitores/consumidores em potencial possam adquirir o livro/produto anunciado com a certeza de que o produto em questão é de primeira linha. No extremo, essa origem é pouco importante porque, sendo um produto, o livro também entra na dinâmica da fetichização da mercadoria. Mais ainda, o próprio Geovani Martins é fetichizado, haja vista a pouca importância de sua origem, que é esmaecida, no comentário de Prata, quando lança foco, reitere-se, em uma predicação autocentrada: "Geovani Martins é um escritor, ponto...".

Após essa caracterização inicial, Prata joga luz, com avaliações breves, em alguns contos do livro, e, ao fazê-lo, não tem como escapar da origem de Geovani Martins, sinalizando, inclusive, para a clara inspiração autobiográfica do jovem autor na produção dos contos. Talvez escudado pela brecha dos comentários a alguns contos, Prata põe em evidência o incontornável tema da exclusão social no Brasil tomada como matéria-prima por Martins na composição de seus contos, ao encenar distintos desdobramentos dessa exclusão, quando focaliza eventos da sociedade brasileira ainda presentes em nossa memória coletiva, tais como o fenômeno dos rolezinhos, que dá título a um dos contos, "Rolézim" ou, ainda, a instalação da Unidade de Polícia Pacificadora em algumas favelas do Rio de Janeiro, o que é tomado como material de encenação para outro conto intitulado "A história do Periquito e do Macaco". Ao comentar este conto, Prata, ou melhor, o enunciador que ele constrói, parece se contradizer quando de sua sugestão sobre ser pouco importante a origem de Geovani Martins. Diz Antonio Prata

\footnotetext{
Situado [o conto "A história do Periquito e do Macaco"] em 2013, quando a maioria da classe média carioca ainda via a iniciativa do secretário de Segurança José Beltrame como a panaceia contra todos os males, o conto mostra que, para a população sob o controle da polícia, o segundo $\mathrm{P}$ da sigla [UPP] não era exatamente uma realidade. (PRATA, Antonio [Orelha do livro])
}

Note-se, aí, uma aproximação maior de Prata do contexto social retomado por Martins, que se vale desse contexto como matéria de fabulação para expor, segundo Prata, uma outra história, contrária ao discurso oficial, no que se refere à instalação da chamada Unidade de Polícia Pacificadora, a UPP, nas favelas da cidade do Rio de Janeiro. Nesse 
momento, Prata parece se dirigir, de modo irônico, diretamente a um público leitor que, em certa medida composto pela classe média ${ }^{8}$, seja ela carioca ou não, talvez ainda tenha a crença de que o segundo P de UPP signifique "pacificadora".

Já caminhando para a finalização da orelha do livro, Antonio Prata aprecia o trabalho com a trama narrativa realizada por Geovani Martins e o contrapõe a outros autores, em certa medida não computados como bons escritores por Antonio Prata, que diz: "Na literatura brasileira contemporânea, que tantas vezes negligencia a trama em favor de supostas experimentações formais, $O$ sol na cabeça surge como uma mais que bem-vinda novidade.” (grifos meus). Nessa avaliação, é possível entrever um conceito de boa literatura: aquela atenta ao que ele chama de "trama", sem, no entanto, nenhuma especificação sobre o que seria essa trama. Por outro lado, ao tachar algumas produções como "supostas experimentações formais", Prata coloca em dúvida tais experimentações e, por extensão, questiona o valor de obras que possivelmente adotem esse vezo.

Amparado por uma avaliação (supostamente?) crítica, Prata acaba por direcionar um tipo de leitura e de literatura a um seu possível leitor (e consequentemente do livro de Geovani Martins), principalmente aquele que lê a orelha assinada por ele ou já o tenha lido em outras oportunidades, seja a leitura de outros comentários ou as próprias produções literárias de Antonio Prata. À primeira vista, esse parâmetro de "boa literatura" pode ser algo corriqueiro, banal. Mas não deixa de ser a formulação de um parâmetro que, inclusive, reforça a cadeia editorial de que faz parte o próprio Antonio Prata e, agora, Geovani Martins, numa espécie de retroalimentação dessa cadeia.

Após finalizada a leitura do comentário de orelha feito por Antônio Prata, na quarta capa, há dois outros comentários sobre o livro: um breve e outro brevíssimo, mas cujos efeitos, em termos de valoração do livro em questão, tornam-se comentários poderosíssimos. O primeiro comentário, reproduzido a seguir, é de João Moreira Salles: "Geovani pula da oralidade mais rasgada para o português canônico como quem respira. Uma nova língua brasileira chega à literatura com força inédita.”. Tradicionalmente, a quarta capa de um livro contextualiza o teor do livro para o leitor, auxiliando-o a compreender esse teor. Podem constar, ainda, comentários elogiosos, geralmente curtos, assinados por pessoas que tenham bom acúmulo de capital simbólico na esfera de circulação de que o livro faz parte. João Moreira Salles é empresário, documentarista, roteirista e produtor do cinema brasileiro. Filho de Walther Moreira Salles - que foi Ministro de Estado e embaixador brasileiro, além de banqueiro -, João Moreira Salles, em 1987, em parceria com seu irmão Walter Salles, fundou a Videofilmes, que conta com mais de 150 produções cinematográficas. Como se pode notar, João Moreira Salles concentra, em alto teor, capital econômico, social, intelectual e simbólico referidos por Thompson (2012) e que são imprescindíveis para a movimentação exitosa de uma cadeia editorial.

Dito isso, o comentário feito por Salles ao livro de Geovani Martins assume uma forte implicação de divulgação e promoção. Pelo teor, é possível ler um enunciador que busca lançar luz em algo caro a toda e qualquer "boa literatura": a língua. Esse enunciador

\footnotetext{
${ }^{8}$ Não perdendo de vista que o livro é um produto, seu consumo, numa sociedade tão desigual como a brasileira, ainda está relegado às classes com maior poder aquisitivo. Inclui-se, aí, por isso, a classe média.
} 
elege a língua como o fiel da balança, distinguindo-a entre o que chama "mais pura oralidade" e "português canônico". Nesse momento, de modo apreciativo, Salles predica Geovani Martins como uma espécie de perito da língua - afinal, ele sabe ir de uma variante a outra "como quem respira", ou seja, com fluidez, naturalidade e perícia. A partir daí, a segunda parte do comentário de Salles funciona como uma premissa de conclusão derivada de duas outras: a oralidade da língua portuguesa e seu uso canônico. E essa premissa conclusiva eleva o livro de Geovani Martins ao sugerir que o domínio dos dois registros linguísticos - uma socialmente prestigiada e a outra, a depender do estrato social que o utiliza, nem tanto - desemboca numa "nova língua brasileira". Vejase que essa conclusão intensifica o aspecto valorativo atribuído ao livro de Geovani Martins, ao se mobilizar os imaginários relativos à ideia de norma linguística. Em certa medida, o comentário de Salles reitera o comentário afixado na capa do livro, onde, conforme já analisado, lê-se em caixa alta: "o novo fenômeno literário brasileiro vendido para 9 países". Sendo um fenômeno, nada mais natural do que a capacidade de escrever (ou criar?) "uma nova língua brasileira." Ao fim e ao cabo, o comentário de Salles, reiterando o comentário de orelha feito por Antonio Prata, talvez esteja ancorado na tensão entre dois mundos que permanecem justapostos, afinal, "pular da oralidade mais rasgada para o português canônico" (grifo meu) é subordinar um registro linguístico a outro, o inculto ao culto. E nessa subordinação permanece uma mirada semelhante à que o enunciador de Antonio Prata sugere ao minorar a importância da origem de Geovani Martins. Novamente, no comentário de Salles, essa minoração se insinua. Afinal, não basta a "oralidade mais rasgada", é preciso que dela se passe, ou melhor, pule para o "português canônico". Permanece, portanto, uma mirada classista (para se dizer o mínimo), empenhada em manter uma relação em que cada um esteja no devido lugar, sem que jamais se discuta, porém, o lugar devido a cada um.

Por fim, o segundo e último comentário, também na quarta capa, logo abaixo do comentário de João Moreira Salles, resume-se ao sintético e potente "Fiquei chapado.", assinado por ninguém menos que Chico Buarque. Dada a grandeza de Chico Buarque ${ }^{9}$, é aqui desnecessário apresentá-lo. E essa não necessidade é a prova cabal de seu reconhecimento como um grande artista fora e dentro do Brasil. Apenas a título de atualização da biografia de Chico Buarque, em 2019, o autor foi laureado com o Prêmio Camões, um dos mais importantes prêmios literários internacionais para autores de língua portuguesa, além de já ter recebido, mais de uma vez, o Prêmio Jabuti, talvez o mais importante prêmio literário do Brasil.

\footnotetext{
9 À semelhança de Antonio Prata e João Moreira Salles, Chico Buarque também nasceu em berço de ouro. Como se sabe, Chico Buarque vem de uma linhagem familiar extremamente importante e influente na história da intelectualidade brasileira. Basta citar seu pai, um dos mais proeminentes pensadores brasileiros sobre a estruturação da sociedade brasileira. Raízes do Brasil, a despeito de críticas, feitas, atualmente, de modo contundente pelo sociólogo Jessé Souza, é, ainda, obra de referência na academia brasileira para se compreender o Brasil. Nesse sentido, a despeito do reconhecido talento de Chico Buarque, vale apontar essa sua origem familiar calcada na erudição e intelectualidade, ironicamente apagada, no caso de Geovani Martins, no comentário de orelha feito por Antonio Prata. Nesse sentido, novamente, vale reiterar, como se fez no caso de Antonio Prata e João Moreira Salles, a ampla rede de capitais que envolve o nome de Chico Buarque a fim de que sempre se possa atentar para as naturalizações de valor que circulam socialmente. Indagar-se sobre as origens e condições desse valor é um exercício crítico sempre necessário e importante.
} 
Relativamente ao enxuto comentário de Chico Buarque que compõe a cadeia editorial de $O$ sol na cabeça, talvez valha a pena repisar uma das grandes características da obra de Buarque: sua grande sensibilidade como poeta (poeta no sentido de criador) ao unir o popular e o erudito de modo que um termo não anule ou subordine o outro. É exatamente o que argumenta o crítico literário e poeta Augusto Massi (1991) sobre essa questão, ao dizer que "esta é uma característica de sua poética (de Chico Buarque), o estabelecimento de uma relação reversível, por isso mesmo enriquecedora, entre o popular e o erudito". (MASSI, 1991, p.194).

Trabalhando sempre nas (im)possibilidades da ambiguidade e do paradoxo, Chico Buarque cria imagens memoráveis em sua obra. A título meramente de retomada, lembremos de "Geni e o Zepelim". No lugar de construir Geni como uma personagem plana, apenas vítima das aflições que o povo da cidade a infligia, Chico Buarque consegue mostrar a faceta caprichosa de Geni (cujo nome, já sinalizado pela crítica, é também ambíguo) que só aceita saciar o comandante que ameaçara explodir toda a fíctícia cidade encenada na música, após as súplicas dos cidadãos entre os quais estavam o prefeito, o bispo e o banqueiro. Para não mais alongar o comentário à referida música, vale a pena redizer que nas contraposições que frequentemente são vistas na obra de Chico Buarque quanto ao popular e o erudito, os termos em contraposição encontram-se numa relação de complementaridade e reversibilidade, e não de subordinação ou dicotomia. Perceber esse ethos em Chico Buarque pode ajudar na interpretação de seu comentário ao livro de Geovani Martins.

Ao construir um enunciador que diz "Fiquei chapado", Chico Buarque faz sua voz coincidir com a enunciação na qual se cria esse enunciador, marcado no verbo flexionado em primeira pessoa. É possível, ainda, perceber que o "chapado", ao funcionar como um predicativo do sujeito, atribui um estado de embriaguez ao sujeito da enunciação. Há uma espécie de fusão entre o popular e o erudito sem que se possam identificar as medidas de um e de outro. O termo "chapado", significando ficar surpreso, arrebatado, vem associado, como já dito, à embriaguez, conotando um êxtase pelo excesso tanto de álcool, quanto de outras drogas, lícitas ou não. E exatamente aí parece residir a fusão entre o popular e o erudito. Uma coisa é ficar chapado consumindo, por exemplo, whisky, outra coisa é ficar chapado consumindo cachaça. O efeito, ficar chapado, é o mesmo, mas o produto consumido para tal fim adquire distintas valorações. Talvez, por isso mesmo, Chico Buarque seja capaz de "ficar chapado" tanto com o que é considerado erudito, quanto com o que é qualificado como "popular" e, ainda, com aquilo que é ilícito e, por isso, precisa ficar silenciado, camuflado na potente ambiguidade de seu comentário. Nesse sentido, portanto, é possível ler, na mão contrária dos outros enunciadores já analisados, uma insinuação de que a demarcação de fronteiras - entre o popular e o erudito, entre o lícito e o ilícito, entre a estirpe familiar "nobre" versus a condição "plebeia”, entre a origem geográfica de prestígio e aquela sem prestígio, entre a oralidade rasgada e o português canônico - por não serem claras, igualmente não seriam critérios muito adequados para a apresentação tanto do livro, quanto do próprio autor. 
Indo mais adiante na análise do comentário, é preciso destacar que Chico Buarque é encenado ${ }^{10}$ como leitor de Geovani Martins numa inversão de posições em que o grande autor "sai" dessa posição e passa a ser o leitor de um autor "menor", ainda em construção, muito mais novo, mas pelo qual a Companhia das Letras nutre grande aposta como "o novo fenômeno" editorial de seu catálogo. Essa inversão de posições enunciativas, estrategicamente explorada pela Companhia das Letras, ao deslocar Chico Buarque para a posição de leitor de Geovani Martins, até então desconhecido do grande público, acaba por deslocar também o potencial leitor/consumidor do livro. Isso porque, ao ler uma "confissão" de Chico Buarque, que se torna leitor de Geovani Martins, esse leitor/consumidor em potencial, poderá ficar bastante inclinado em adquirir o livro em questão, que se tornará, frise-se, o livro lido por Chico Buarque. Saliente-se, por fim, que o sintético comentário de Chico Buarque, contrariamente aos de Prata e Salles, comunica uma experiência de leitura/consumo. Não é um comentário "técnico" ou crítico, conforme se pode depreender tanto do texto de Prata, quanto do texto de Salles. Enquanto esses dois últimos falam sobre o livro de Geovani, referenciando-o, Chico Buarque fala com Geovani Martins ao comunicar seu estado como leitor arrebatado diante da obra lida. Fala, ainda, com o possível leitor/consumidor de $O$ sol na cabeça, numa enunciação que se constrói interpenetrando distintas identidades: o músico, o poeta, o romancista, o compositor, o escritor premiado, o artista consagrado, entre várias outras identidades que se tornam capitais altamente valiosos na constituição e consolidação de seu nome e carreira. Capitais esses, não por acaso, "emprestados" a Geovani Martins no manejo de criação do livro realizado pela Companhia das Letras.

\section{CONSIDERAÇÕES FINAIS}

Os agentes da cadeia editorial do livro $O$ sol na cabeça aqui analisados, compreendidos numa perspectiva enunciativa são, ainda, a parte da cadeia autorizada a falar. Tais agentes, ao serem encenados de diversas formas nos comentários ao livro de Geovani Martins, fazem parte de uma enunciação maior que diz respeito à promoção e divulgação da obra. Essa enunciação maior, por sua vez, é orquestrada pela Companhia das Letras que recorre à própria estruturação do design editorial do livro - a capa, as orelhas e a quarta capa - como espaços nos quais se constrói uma rede de valorações, a fim de atribuir valor ao produto em divulgação, promovendo-o.

A análise enunciativa empreendida dos quatro comentários - o da capa, o das orelhas e da contracapa - apontou, em síntese, para as seguintes imagens relativas ao livro e, por extensão, a seu autor: Geovani Martins como um autor extraordinário, como um jovem autor sendo oficialmente apresentado à comunidade leitora, sendo um cultivador da "boa literatura", como um perito no manejo da língua e, por fim, como um autor embriagante.

Interessa, no entanto, observar que os comentários ao livro, habilmente manejados pela editora, de maneira estratégica no sentido de promover e divulgar seu produto, embora tenham esse fio de apreciação e atribuam valor ao livro, conforme se demonstrou

\footnotetext{
${ }^{10}$ Não se perca de vista que a composição editorial da obra, incluindo aí os comentários que vão compô-la, são estratégias manejadas pela Companhia das Letras. Não há, pelo comentário de Chico Buarque, uma garantia de que ele tenha ou não lido o livro. Apesar disso, o que importa é perceber o manejo estratégico da editora ao apresentar esse comentário e os possíveis efeitos daí decorrentes.
} 
na análise apresentada, indiciam, também, outras leituras, dentre as quais se destaca o apagamento da origem de Geovani Martins, um escritor que nasceu na periferia do Rio de Janeiro, marcada pelas imagens de tráfico e violência, veiculadas (e forjadas?) principalmente pela grande mídia brasileira. ${ }^{11}$ Há, ainda, a tentativa de forjar uma identidade autoral para Geovani Martins ao associá-lo a grandes nomes do circuito editorial brasileiro que já estão consagrados.

Essas leituras deixam entrever aquilo que talvez seja a pedra de toque de nossa sociedade: a intransponível fronteira das classes sociais. Companhia das Letras, a maior editora brasileira, João Moreira Salles, Antonio Prata e Chico Buarque formam uma espécie de cinturão de valor editorial que decide qual autor (qual livro, portanto) será ou não acolhido na composição e renovação desse cinturão que se retroalimenta. Há um ranço classista que modula os comentários analisados. Em menor grau, talvez, no comentário de Chico Buarque que, embora pertença a uma elite econômica e intelectual brasileira, munido de grande sensibilidade artística, consiga, por isso mesmo, avançar e questionar esse cinturão, ainda que a partir desse lugar. Já os comentários de Prata e Salles sabem mais a esse ranço. Salles se apoia em um cânone de língua, já Antonio Prata parece querer forjar a imagem de um autor cuja origem se funda em sua própria condição de autor, o que se mostra como uma premissa circular, tautológica e, portanto, autocentrada. Afinal, como convencer os possíveis leitores/consumidores do produto em promoção de que um autor nascido em Bangu, morador da Rocinha e do Vidigal merece ser lido?

A palavra, nos ensinam Bakhtin e Volochínov (2009), é uma arena em que se defrontam distintas entoações. A língua, como um fenômeno ideológico, não deve ser dissociada "do ser social que nela se refrata e das condições socioeconômicas refratantes." (BAKHTIN; VOLOCHÍNOV, 2009, p. 202). E é por isso mesmo que "não se pode construir uma enunciação sem modalidade apreciativa. Toda enunciação compreende antes de mais nada uma orientação apreciativa. É por isso que, na enunciação viva, cada elemento contém ao mesmo tempo um sentido e uma apreciação." (BAKHTIN; VOLOCHÍNOV, 2009, p. 140, grifo dos autores).

Assim, a cadeia editorial, marcada pelos distintos capitais que a constituem, segundo se viu com Thompson (2012), pode também ser compreendida como uma arena/cadeia enunciativa, conforme se evidenciou na análise apresentada. A mercadoria, forma que assume um trabalho humano na dinâmica capitalista, apaga todas as condicionantes que envolveram o trabalho realizado para que ela fosse criada pelas mãos de homens e mulheres.

Nesse sentido, parte da cadeia editorial autorizada a falar, além de edulcorar a origem de Geovani Martins, forjando-lhe, para tanto, uma identidade autoral palatável, silencia outra parte da mesma cadeia, que não é autorizada a falar - os que trabalham com os braços, com mãos, com os olhos, mas não diretamente com a escritura. Por isso mesmo, os comentários laudatórios ao livro de Geovani Martins, longe de serem singelos e despretensiosos elogios a esse jovem autor brasileiro, atuam no sentido de promover e divulgar um produto, enquanto se apagam as distintas relações de poder e produção envolvidas tanto na cadeia editorial, quanto na cadeia enunciativa encenada e feita circular na capa, nas orelhas e na quarta capa do livro $O$ sol na cabeça.

${ }^{11}$ Recorde-se, por exemplo, que o Rio de Janeiro, novamente, durante o governo Temer, passou por intervenção do Exército brasileiro. Fato amplamente noticiado na grande mídia brasileira em tom majoritariamente de aprovação. 
ARAÚJO, E. A construção do livro: princípios de técnica e editoração [recurso eletrônico]. Rio de Janeiro: Lexicon, 2012.

BAKHTIN, M; VOLOCHÍNOV, V. N. Marxismo e filosofia da linguagem. Tradução de Michel Lahud e Yara F. Vieira. 13. ed. São Paulo: Hucitec, 2009.

BAKHTIN, M. Questões de Literatura e de Estética: a teoria do romance. Trad. Aurora Fornoni Bernardini et. al. 6. ed. São Paulo: Hucitec, 2010.

BENVENISTE, E. Problemas de Linguística Geral I. Tradução de Maria da Glória Novake Maria Luísa Neri. 4. ed. Campinas, S.P.: Pontes, 1995.

BENVENISTE, E. Problemas de Linguística Geral II. Tradução de Eduardo Guimarães et al. Revisão técnica da tradução Eduardo Guimarães. 2. ed. Campinas, S.P.: Pontes, 1989 (vol. II).

BOURDIEU, P. The Forms of Capital. In: Handbook of Theory and Research for the Sociology of Education. Edited by J. G. Richardson. New York: Greenwood Press, 1986, p. 241-258. Disponível em: encurtador.com.br/rIOY4 . Acesso em: 15 nov. 2019.

BOURDIEU, P. Sobre a televisão. Tradução de Maria Lúcia Machado. Rio de Janeiro: Jorge Zahar, 1997. CAVALLO, G; CHARTIER, R. Introducción. Trad. María Barberán. In: CAVALLO, G; CHARTIER, R. (Org.). Historia de la lectura en el mundo occidental. Madrid: Grupo Santillana de Ediciones, 2001. p. 15-63.

CHARTIER, R. A aventura do livro: do leitor ao navegador. Trad. Reginaldo Carmello Corrêa de Moraes. São Paulo: Editora UNESP, 1998.

MARTINS, G. O sol na cabeça. São Paulo: Companhia das Letras, 2018.

MARX, K. A mercadoria. In: MARX, K. O capital: crítica da economia política. Tradução de Regis Barbosa e Flávio Kothe. São Paulo: Nova Cultura, 1996, p. 165-208.

MASSI, A. Estorvo. In: Novos Estudos CEBRAP, São Paulo, 1991, p. 193-198.

THOMPSON, J. B. Introduction. In: THOMPSON, J. B. Merchants of culture: The publishing business in the Twenty-First Century. Cambridge: Polity, 2012, p. 13-23.

ANEXOS: CAPA, CONTRACAPA, ORELHAS

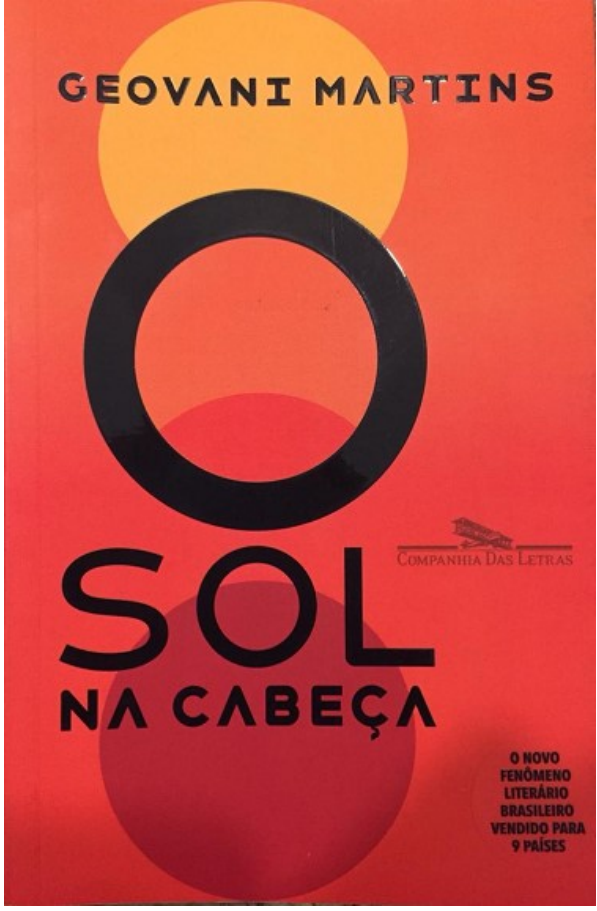

Anexo 1 - Capa

Fonte: Foto do autor

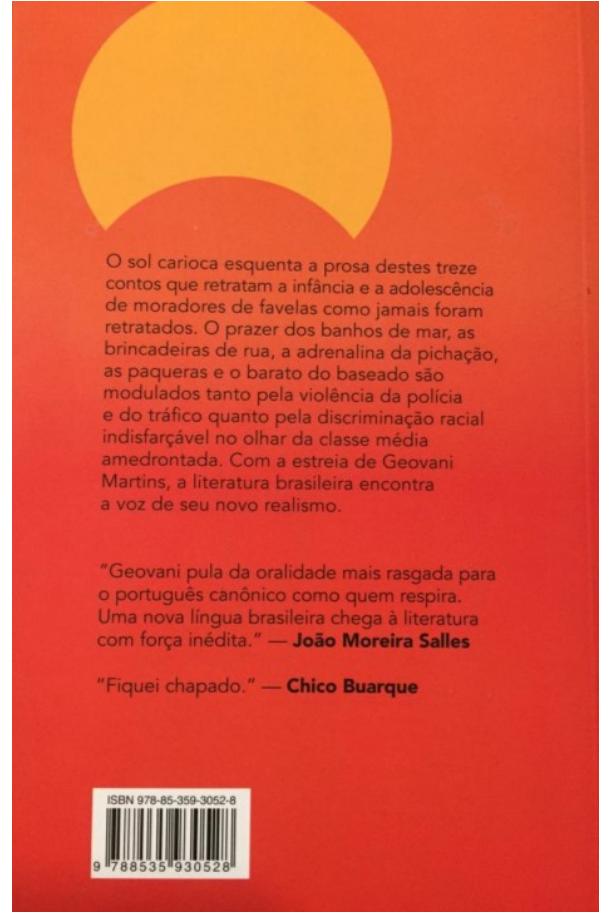

Anexo 2 - Contracapa

Fonte: Foto do autor. 
Vai chegar o dia em que a orelha de um livro do Geovani Martins poderá ignorar o fato de que ele é um escritor nascido em Bangu e morador da Rocinha ou do Vidigal, porque Geovani Martins é um escritor, ponto quando fala de uma relação amoro sa, em "A viagem"; sobre a infância, em "O caso da borboleta", ou sobre qualquer outro assunto, o faz com o talento e a sensibilidade de um narrador habilidoso, pouco importando sua origem.

Neste primeiro livro, porém, a inspiração autobiográfica é clara, e a força dos contos é inseparável do lugar de onde o autor vê o mundo. Nos treze textos de $\mathrm{O}$ sol na cabeça, acompanhamos a infância e a adolescência de garotos para quem às angústias e dificuldades próprias da idade soma-se a violência de crescer no lado menos favorecido da "Cidade partida", o Rio de Janeiro das primeiras décadas do século XXI.

Em "Rolézim", uma turma de adolescentes vai à praia no verão de 2015, quando a PM fluminense, em nome do combate aos arrastões fazia marcaçāo cerrada aos meninos de favela que pretendessem chegar às areias da Zona Sul. Em "A história do Periquito e do Macaco", assistimos às mudanças ocorridas na Rocinha após a instalação da Unidade de Policia Pacificadora, a UPP. Situado em 2013, quando a maioria da classe média carioca ainda via a iniciativa do secretário de Segurança José Beltrame como a panaceia contra todos os males, o conto mostra que para a população sob o controle da

\section{Anexo 3 - Primeira orelha}

Fonte: Foto do autor polícia, o segundo P da sigla não era exatamente uma realidade. Em "Estação Padre Miguel", cinco amigos se veem sob a mira dos fuzis dos traficantes locais.

Nesses e nos outros contos, chama atenção a capacidade narrativa do escritor, pintando com cores vivas personagens e ambientes sem nunca perder o suspense e o foco na ação. Na literatura brasileira contem porânea, que tantas vezes negligencia a trama em favor de supostas experimentaçōes formais, $\mathrm{O}$ sol na cabeça surge como uma mais que bem-vinda novidade.

\section{Antonio Prata}

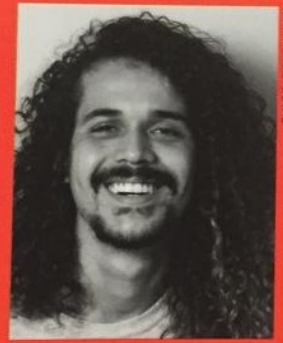

GEOVANI MARTINS nasceu em 1991, em Bangu, no Rio de Janeiro. Trabalhou como "homem-placa" atendente de lanchonete, garçom em bufê infantil e barraca de praia. Em 2013 e 2015, participou das oficinas da Festa Literária das Periferias, a Flup. Publicou alguns de seus contos na revista Setor $X$ e foi convidado duas vezes para a programação paralela da Flip.

\section{Anexo 4 - Segunda orelha}

Fonte: Foto do autor.

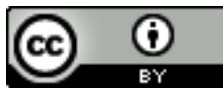

Este texto está licenciado com uma Licença Creative Commons Atribuição 4.0 Internacional. 